- Developing the research question is the critical first step in research.

- Three broad categories of question can be identified: Descriptive questions (for example Who? What? Where? When?); Questions of relationships (How are two or more data-items related?); Questions of comparison (often these questions will ask about cause and effect).

- In order to develop the research question, a careful exploration of previous research should be conducted. This article identifies several useful resources to assist the general dental

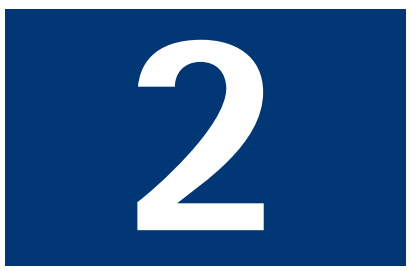
practitioner in undertaking this task.

\title{
Research in primary dental care Part 2: Developing a research question
}

\author{
J. T. Newton ${ }^{1}$, E. J. Bower ${ }^{2}$ and A. C. Williams ${ }^{3}$
}

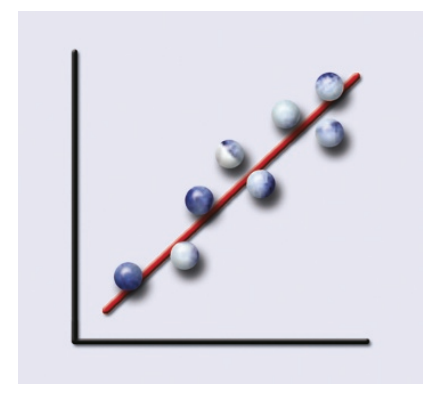

The first step in planning and conducting any research is identifying the research question, that is a testable statement of the
question which the research aims to answer. In this article three distinct types of research question are identified: Descriptive
questions (for example Who? What? Where? When?); Questions of relationships (How are two or more things related?);
Questions of comparison (often these questions will ask about cause and effect). Examples are given of each type of research
question. The process of devising a research question is described, in particular searching for relevant information, and
evaluating the quality of the information obtained. A list of useful resources is provided.

RESEARCH IN PRIMARY DENTAL CARE

1. Setting the scene

2. Developing a research question

3. Designing your study

4. Measures

5. Devising a proposal, obtaining funding and ethical considerations

6. Data analysis

7. Writing up your research

${ }^{1 *}$ Professor of Psychology as Applied to Dentistry, Department of Dental Public Health \& Oral Health Services Research, GKT Dental Institute, Caldecot Road, London SE5 9RW; ' GDP, Staff Dental Service, Eastman Dental Hospital, 256 Gray's Inn Road, London WC1X 8LD; ${ }^{3}$ Consultant Senior Lecturer in Orthodontics, Department of Child Dental Health, University of Bristol Dental School, Lower Maudlin St, Bristol BS1 2LY ${ }^{*}$ Correspondence to: Prof. J. T. Newton Email:Tim.Newton@kcl.ac.uk

\section{Refereed Paper}

doi:10.1038/sj.bdj.4811285

( ) British Dental Journal 2004; 196:

605-608
In the first article in this series we suggested that research is a process of asking questions and using highly-structured techniques to answer these questions. Identifying the right question to address is an important first step in the research process $^{1}$ (see Fig. 1). In this article we will look at ways of devising and revising a research question, commencing with an initial idea and focussing this into a testable research question. This process is described in Figure 2.

\section{DECIDE ON YOUR QUESTION}

In deciding which area to focus on as the topic of your research, you should consider:

- How important is the topic under consideration to me and my patients?

- What is the size of the problem?

- How realistic is it to study this topic?

Carrying out research requires a degree of self-motivation. If the topic that you have chosen to study is neither interesting nor important to you, then it seems likely that you will become disinterested and decide to give up the research. Research will involve carrying out data collection, and in order to ensure that you get interesting and valid findings you will need to acquire a certain amount of data. If you choose to study something which, though interesting, is rare in general dental practice then it is likely to take you a long time to collect sufficient data to make meaningful statements. For example, you may want to study the reasons associates give for leaving your practice. If an associate leaves only once every 2 to 3 years, then it will take a long time to obtain a sample of more than 10 ! However, small sample sizes can be useful in describing interesting phenomena - for example case studies provide descriptions of unusual diseases or reactions.

Having decided on the broad topic area, we need to phrase our research as a question. Research generally tries to answer one of three types of questions. These are:

- Descriptive questions

- Questions of relationships

- Questions of comparison.

Descriptive questions

Who? What? Where? When? Description forms the basis of all research. Any new area of investigation must start with the description of phenomena. Examples of the type of study which asks a descriptive question might include case studies, and descriptions of the prevalence and incidence of oral disease. For example, a case study in the British Dental Journal has described the adverse effects of tongue piercing. ${ }^{2}$ Other examples of descriptive studies include an exploration of dental patients' preferred roles in treatment decision-making, ${ }^{3}$ and a study of the factors influencing dentists' choice of restorative materials. ${ }^{4}$ The Adult Dental Health Survey provides descriptive information on the presence of dental disease among adults in the UK. ${ }^{5}$ 


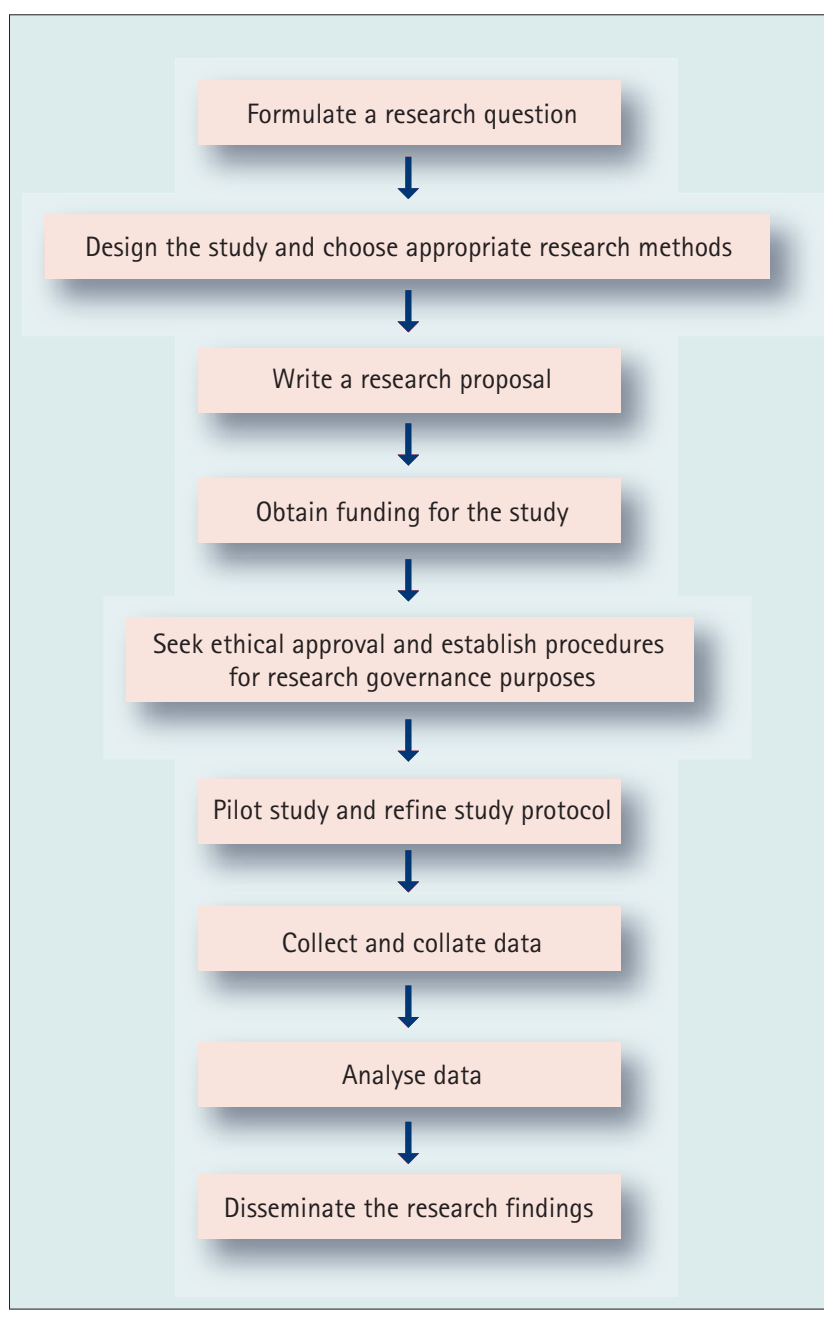

\section{Questions of relationships}

Questions of this type ask how phenomena are related. For example, the classic studies of fluoridation noticed an association between low levels of caries and the presence of fluoride in the water. Recent studies of this sort have included an exploration of the relationship between dental anxiety, dental attendance and treatment history in 5-year-old children, ${ }^{6}$ and a study of the relationship between orofacial pain and social deprivation. ${ }^{7}$

In primary care, relationships between phenomena might provide useful information for the planning of your practice. Are patients more likely to fail an appointment for a dentist, or for the hygienist? Are failures to attend related to the time of school holidays? Are complex fillings more likely to fail than simple ones?

\section{Questions of comparison}

In comparing two things we are often trying to determine cause and effect. For example, if we give one individual (or group of individuals) a particular treatment does that improve their outcome in comparison to an individual (or group of individuals) who did not receive that treatment? In order to demonstrate cause and effect it is important to ensure that the only possible cause is the variable of interest. The randomised control trial (RCT) is the gold stan- dard technique for demonstrating cause and effect relationships. In an RCT two groups are compared that differ only in the one variable under study. So, for example if we wanted to determine if providing patients with a written quotation prior to commencement of treatment increased the likelihood of patients completing the course of treatment, we would compare two groups of patients who differed only in whether or not they had received the written quotation. Drawing on a large sample of patients we would randomly allocate patients to either the control group (no written quotation) or experimental group (written quotation given). Any difference between the groups could then be attributed to the 'cause' receiving a quotation. An example of this type of study is provided by Seymour et al. who investigated the comparative efficacy of aspirin and paracetamol in relieving postoperative pain after third molar surgery. ${ }^{8}$

\section{Identify previous studies}

In looking for previous studies on which to base your research, bear in mind that you want to seek out information not only on the findings of previous studies but also on the methods and measures that they used. Consulting the Cochrane Library to see whether a systematic review of the subject has been published would be a useful starting point. Sources of information on published studies are listed below:

- Computerised databases eg MEDLINE, Cochrane Library

- National Electronic Library for Health

- Health Information for London Online

- BDA library

- Back copies of the BDJ

- Other people, in particular academic departments (ask at CPD), other GDPs.

In using computerised databases it is important to choose appropriate key words. Key words are those entered as search terms. Articles containing the key words will be selected by the computer as suitable. It is not uncommon to find that the first two or three searches yield little that is relevant to your own research idea. The process requires some perseverance. Once you have found an article which is relevant, use the key words contained in that paper to find similar articles. Alternatively look for other articles by the same authors - they might also be relevant.

The National Electronic Library for Health is an online health library for the public, patients and NHS staff (see Table 1). It provides current, evidence-based information on a wide variety of health, treatment and quality issues, and gives details of protocols and care pathways, National Service Frameworks, National Institute of Clinical Excellence reports, health policies etc. There are several very useful links to key databases such as MEDLINE and the Cochrane Library, and there are links to other websites such as the Department of Health, Commission 
for Health Improvement, NHS Modernisation Agency, public health sites etc. At the time of writing, parts of the oral health library are still under development.

For GDPs who live or work in London and the south-east of England, and provide treatment on the NHS, Health Information for London Online is an online source of health-related knowledge, databases and full-text journals (see Table 1).

The BDA provide a very useful library service which draws not only upon journal-based resources, but also books, government documents and a range of other information which will provide a useful background to your study.

Sifting through back copies of the $B D J$ may provide some useful information on the subject matter of your proposed research. As well as the articles, try looking through the abstracts of recent research. Finally a useful source of information is other researchers, either academic members of staff or other general dental practitioners.

\section{OBTAIN MATERIAL}

Obtaining copies of journal articles is relatively easy. The BDA is a useful resource and is willing to help members with their enquiries. There may be a fee for some types of materials. Information may available on the internet, for example government documents and some journal articles. MEDLINE contains abstracts of research which may be a useful way to decide whether it is worth obtaining a paper. Remember though that reading the abstract is not a substitute for reading the whole paper.

\section{EXAMINE THE QUALITY AND OUANTITY OF THE INFORMATION}

Having gained all this information, it is important to make some judgements about the quality of the information obtained. It is important to consider both the extent to which the information you have obtained is relevant to your research question, and the quality of the information itself.

\section{Judging the relevance of the published research}

In judging the relevance of the research you should address three questions, as follows:

- What is the question addressed by the research?

- How is that similar/different to your research question?

- How would the research that you are planning extend the published research?

This will allow you to identify how the research described differs from your planned research, and how you might add to the knowledge in the published literature. Focus not only on the question that the research asked but on the types of methods that were used.

\section{Judging the quality of published research}

It is important to read any articles that you find with a critical eye. However bear in mind that

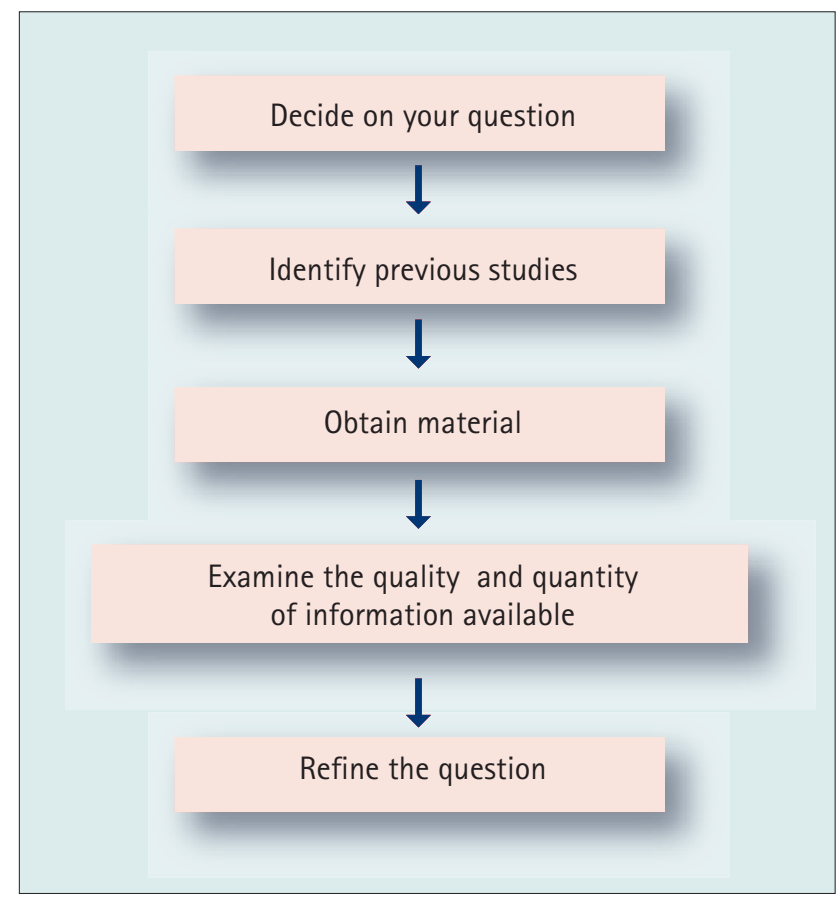

Fig. 2 Devising and revising your research question

you should not be too critical - no research is perfect and part of the skill of research is to identify the weaknesses of a particular design and to develop methodological approaches to overcome these weaknesses. Having decided what

\section{Table 1 Useful publications and websites}

\section{Searching databases:}

1. Stave C D. Field guide to Medline - making searching simple. Philadelphia: Lippincott, Williams \& Wilkins, 2003.

2. Downes P K. Successful web searching. Br Dent J 1998; 185: 393-399.

3. Greenhalgh T. How to read a paper. London: BMJ Books, 2001. (Chapter 2)

Critical appraisal of the published literature:

1. Greenhalgh T. How to read a paper. London: BMJ Books, 2001.

2. Crombie I M. The pocket guide to critical appraisal. London: BMJ Publication, 1996.

Information resources:

The PubMed version of Medline can be accessed free of charge at: www.ncbi.nlm.nih.gov/entrez/query.fcgi

The Cochrane Library can be accessed free of charge at: www.nelh.nhs.uk/cochrane.asp

The National Electronic Library for Health (NeLH) is found at:* www.nelh.nhs.uk

Health Information for London Online (HILO) is found at:* www.hilo.nhs.uk

The National Research Register gives details of current projects and can be found at: www.update-software.com/national/

A list of priority areas for research in primary dental care as outlined by the NHS Research and Development Programme can be found at:

www.doh.gov.uk/research/rd3/nhsrandd/timeltdprogs/pcdental/pcdental.htm

${ }^{*}$ An Athens password is required to access some sections of the NeLH and most sections of HILO. You can register for an Athens password online, or at your local NHS healthcare library.

Further information on the research process:

A detailed flowchart with a number of excellent links is available at: www.rdinfo.org.uk/flowchart/Flowchart.html 
question the research addresses, explore the following areas:

- Sampling - is the sample representative of the population under study? Are the individuals who took part in the research similar to those you would expect to see in your surgery?

- Measures - are the measurements sensible? Do they measure what they are supposed to measure? Are they reliable/valid?

- Data analysis - is it appropriate to the question? Is the analysis answering the research question?

- Conclusions - what conclusions are drawn?

It is important to take time to frame the research question carefully, drawing on the experiences of other researchers

In later articles in this series we will discuss these areas more fully.

\section{REFINE THE QUESTION}

In the light of the information that you have col-
Three types of research question are identified: questions of description; questions about relationships between phenomena; and questions of comparison. We have outlined an approach to developing the research question and this is summarised in Figure 2. An important component of this approach is reviewing previous literature in this field and we have listed some criteria for judging the quality of published research. However this list is not exhaustive - in later articles we will discuss measurement, and the criteria used to judge the quality of measurement tools. In the next article in this series we will explore the design of a study - that is how to develop a method to answer your question. lected, it is likely that you will refine the question that you are asking. Usually, this will mean focussing the question onto a more specific topic. It is not uncommon to start with a very broad question and for this to be refined into a much more specific question about a particular aspect of the broader question.

\section{SUMMARY}

In this article we have looked at how you would decide on a research question. This is an important first step in the research process the question asked determines the method chosen, the statistics which are adopted and the conclusions which are drawn. It is important to take time to frame the research question carefully, drawing on the experiences of other researchers.
1. Richards D. Asking the right question right. Evidence-Based Dent 2000; 2: 20-21.

2. Theodossy T. A complication of tongue piercing. A case report and review of the literature. Br Dent J 2003; 194: 551-552.

3. Chapple H, Shah S, Caress A-L, Kay EJ. Exploring dental patients' preferred roles in treatment decision-making a novel approach. Br Dent J2003; 194: 321-327.

4. Burke FJ T, McHugh S, Hall A C, Randall R C, Widsham E, Forss H. Amalgam and composite use in UK general dental practice in 2001. Br Dent J2003; 194: 613-618.

5. Kelly M, Steele J, Nuttall N, Bradnock G, Morris J, Nunn J, Pine C, Pitts N, Treasure E, White D. Adult Dental Health Survey: Oral Health in the United Kingdom 1998. London: The Stationery Office, 2000.

6. Milsom K M, Tickle M, Humphris G M, Blinkhorn A S. The relationship between anxiety and dental treatment experience in 5 year old children. BrDent J 2003; 194: 503-506.

7. Aggarwal $V R$, Macfarlane TV, Macfarlane $G J$. Why is pain more common amongst people living in areas of low socioeconomic status? A population-based cross-sectional study. BrDentJ 2003; 194: 383-387.

8. Seymour R A, Hawkesford J E, Sykes J, Stillings M, Hill C M. An investigation into the comparative efficacy of soluble aspirin and solid paracetamol in postoperative pain after third molar surgery. Br Dent J 2003; 194: 153-157. 